\title{
Analysis of the interactome of the Ser/Thr Protein Phosphatase type 1 in Plasmodium falciparum
}

\author{
Thomas Hollin ${ }^{\dagger}$, Caroline De Witte ${ }^{\dagger}$, Astrid Lenne ${ }^{\dagger}$, Christine Pierrot and Jamal Khalife ${ }^{*}$
}

\begin{abstract}
Background: Protein Phosphatase 1 (PP1) is an enzyme essential to cell viability in the malaria parasite Plasmodium falciparum (Pf). The activity of PP1 is regulated by the binding of regulatory subunits, of which there are up to 200 in humans, but only 3 have been so far reported for the parasite. To better understand the P. falciparum PP1 (PfPP1) regulatory network, we here report the use of three strategies to characterize the PfPP1 interactome: co-affinity purified proteins identified by mass spectrometry, yeast two-hybrid (Y2H) screening and in silico analysis of the $P$. falciparum predicted proteome.

Results: Co-affinity purification followed by MS analysis identified 6 PfPP1 interacting proteins (Pips) of which 3 contained the RVxF consensus binding, 2 with a Fxx[RK]x[RK] motif, also shown to be a PP1 binding motif and one with both binding motifs. The $\mathrm{Y} 2 \mathrm{H}$ screens identified 134 proteins of which 30 present the RVxF binding motif and 20 have the Fxx[RK]x[RK] binding motif. The in silico screen of the Pf predicted proteome using a consensus $\mathrm{RV} x \mathrm{~F}$ motif as template revealed the presence of 55 potential Pips. As further demonstration, 35 candidate proteins were validated as PfPP1 interacting proteins in an ELISA-based assay.

Conclusions: To the best of our knowledge, this is the first study on PfPP1 interactome. The data reports several conserved PP1 interacting proteins as well as a high number of specific interactors to PfPP1. Their analysis indicates a high diversity of biological functions for PP1 in Plasmodium. Based on the present data and on an earlier study of the Pf interactome, a potential implication of Pips in protein folding/proteolysis, transcription and pathogenicity networks is proposed. The present work provides a starting point for further studies on the structural basis of these interactions and their functions in P. falciparum.
\end{abstract}

Keywords: Plasmodium, PP1, Interactome, RVxF motif

\section{Background}

Malaria continues to be a major health problem and a leading cause of child mortality of the inter-tropical regions despite extensive research efforts. The present situation is also increasingly complicated by the emergence of parasite resistance to multiple drugs much more rapidly than the development of novel anti-malarials. A major obstacle in devising new control tools is our limited knowledge of basic parasite biology and the paucity of identified potential intervention targets. Plasmodium

\footnotetext{
* Correspondence: jamal.khalife@pasteur-lille.fr

${ }^{\dagger}$ Equal contributors

Center for Infection and Immunity of Lille, Inserm U1019-CNRS UMR 8204

University of Lille Nord de France, Institut Pasteur de Lille, 1 Rue du

Professeur Calmette, Lille, France
}

(c) 2016 Hollin et al. Open Access This article is distributed under the terms of the Creative Commons Attribution 4.0 International License (http://creativecommons.org/licenses/by/4.0/), which permits unrestricted use, distribution, and reproduction in any medium, provided you give appropriate credit to the original author(s) and the source, provide a link to the Creative Commons license, and indicate if changes were made. The Creative Commons Public Domain Dedication waiver (http://creativecommons.org/publicdomain/zero/1.0/) applies to the data made available in this article, unless otherwise stated. that undergo a number of developmental stages in the vertebrate host and the invertebrate vector. During the last decade, several studies strongly indicated that protein phosphorylation and dephosphorylation processes, governed by kinases and phosphatases respectively, play a central and essential role in Plasmodium cell cycle and developmental regulation $[1,2]$.

In Plasmodium falciparum (Pf), the most deadly apicomplexan parasite, efforts have begun for an examination of the biological roles of protein kinases and phosphatases and their potential as drug targets. In this context, biochemical and cloning studies have reported enzymatic activities and the genes of catalytic subunits related to plasmodial phosphatases. These include PfPP1c, PfPP2A, 
PfPP2B and PfPP2C, which have been shown to be highly conserved during evolution, suggesting an essential role for these enzymes [3-5]. With respect to the Pf Protein Phosphatase type 1 catalytic subunit or PfPP1c, it cannot be considered per se as a suitable drug target (> $80 \%$ identity with human and yeast PP1 or GLC7). Indeed, complementation studies showed that PfPP1 was able to rescue yeast mutated in PP1 [6]. In P. falciparum functional studies suggested that its activity predominates over the other phosphatases in blood parasites [7]. Finally, phenotypic PfPP1 gene knockdown and the use of phosphatase inhibitors indicated that it seems to be essential for parasite asexual development in erythrocytes [2, 4]. At this stage, it is important to note that free PP1c seems to be toxic for the cell [8] but a considerable number of proteins interacting with PP1c have been reported that direct the localization, specificity and the level of its activity in yeast and higher eukaryotic cells [9]. Indeed, about 200 proteins have been shown to physiologically interact with PP1c, constituting a 'PP1c platform' that provides a framework offering diverse functions to this enzyme in cell division, transcription and apoptosis for instance [10]. Structural and functional studies revealed that the interaction of regulators with PP1 involved several binding sites, including mainly the so-called $\mathrm{RVxF}$ and SILK motifs $[8,11]$. The most studied binding motif is the RVxF for which it has been established a first short consensus sequence as $[R K] x_{0-1}[\mathrm{VI}]\{\mathrm{P}\}[\mathrm{FW}]$ where $\mathrm{x}$ could be any amino acid and $\{P\}$ any amino acid except $P$ [12].

The importance of these proteins in the regulation of PP1 activity in vitro and in vivo prompted us to identify the regulators of PfPP1c and to address their functions. Our initial focus based on the completion of the Pf genome and the delineation of known PP1 regulators has revealed the existence of four conserved regulators. So far, three gene products, Pf Leucine Rich Repeat 1 (PfLRR1), Pf Inhibitor 2 (PfI2) and Pf Inhibitor 3 (PfI3) have been thoroughly explored to define their functions in this parasite. Biochemical and structure-activity relationship studies demonstrated that these regulators indeed bind to PfPP1. In these studies, we showed that P. falciparum PP1 is submitted to a control of its activity by PfLRR1 (a homolog of yeast SDS22), Inhibitor-2 (PfI2) and -3 (PfI3) with substantial differences compared to the human orthologs for Inhibitor 2 and 3 [13-18]. PfI2 exhibits an inhibitory role on PfPP1 activity, the short RVxF binding motif, not present in human I2, a secondary $\operatorname{Fxx}[R K] x[R K]$ binding motif and a peptide sequence $30 \%$ shorter than its human homolog. PfI3, although it contains the RVxF consensus motif, does not seem to be an inhibitor but rather an activator of PfPP1 in vitro and is unable to complement I3 deficient yeast, suggesting a specific role for PfI3 on PfPP1. In $P$. falciparum, our reverse genetic analyses suggest that
PfI2 as well as PfI3 are essential for parasite growth. Further, NMR analysis showed that the main domain of PfI3 binding to PfPP1 is within residues $\mathrm{P}^{39}-\mathrm{W}^{45}$. The mutation of the RVxF motifs in both proteins significantly affects the binding to PP1. Finally, peptides derived from these binding motifs have been shown to inhibit P. falciparum growth in vitro $[17,18]$.

These observations underscore the importance of PP1 regulators and promote an increased interest to identify P. falciparum PP1 interacting proteins (Pips). In the present work, biochemical approaches, yeast two-hybrid screens and in silico analysis were used to define the Pips that are the starting point to elucidate PP1 interaction networks in $P$. falciparum and to provide new pathways for further studies to reveal potential targets for specific pharmacological intervention.

\section{Results and discussion}

Identification of Pips by affinity/Mass Spectrometry

In order to identify Pips expressed by $P$. falciparum, affinity purification on PfPP1 followed by mass spectrometry was carried out. In this approach, soluble extracts from blood stage parasites cleared as described in Materials and Methods were incubated with PfPP1 covalently bound to sepharose beads. The eluate was separated by SDS-PAGE and the proteins detected by coomassie blue staining were identified by MS-MS. As shown in Table 1 , only 6 P. falciparum proteins were clearly identified based on the number of peptides analysed and the corresponding mascot scores for each protein (Additional file 1: Table S1). The identified proteins, Ornithine aminotransferase, GAPDH and Phosphoethanolamine N-methyltransferase contained the motifs KTVKF, KLVSW and RIIF respectively, which comply with the RVxF consensus sequence, while PfHSP90 and Pf disulfide isomerase have only one putative $\operatorname{Fxx}[\mathrm{RK}] \mathrm{x}[\mathrm{RK}]$ motif (FENRKK and FNKKNK respectively). Sequence analyses of PfHSP70 showed 2 potential binding motifs RLVNF and FKRKNR which correspond to RVxF and $\operatorname{Fxx}[\mathrm{RK}] \mathrm{x}[\mathrm{RK}]$ motifs respectively, supporting a direct interaction. However, it could not be excluded that this interaction may be related to the chaperone functions of HSPs. Hence, it would be necessary to further dissect the role of HSPs on the function of PP1. Previous studies reported that PP1 interacts with murine and human HSP70 $[19,20]$ which are in agreement with the above data. Further, amino acid sequence analysis of PfHSP70 showed $70 \%$ identity with mouse and human HSP70 and 2 potential binding motifs, however only the binding motif $\operatorname{Fxx}[\mathrm{RK}] \mathrm{x}[\mathrm{RK}]$ is present in the latter (Additional file 2: Table S2). Overall, the above approach led to the detection of a low number of direct or indirect Pips when compared to the high number of reported regulators/substrates of PP1c in other 
Table 1 Pips identified by affinity chromatography/mass spectrometry

\begin{tabular}{|c|c|c|c|}
\hline \multirow[t]{2}{*}{ Band $^{a}$} & PlasmoDB & Name $^{c}$ & \multirow{2}{*}{ 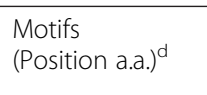 } \\
\hline & Accession number ${ }^{b}$ & & \\
\hline 1 & PF3D7_0708400 & heat shock protein 90 (HSP90) & FENRKK (371-376) \\
\hline \multirow[t]{2}{*}{2} & PF3D7_0818900 & heat shock protein 70 (HSP70) & RLVNF (248-252) \\
\hline & & & FKRKNR (257-262) \\
\hline 3 & PF3D7_0827900 & protein disulfide isomerase (PDI8) & FNKKNK (112-117) \\
\hline 4 & PF3D7_0608800 & ornithine aminotransferase (OAT) & KTVKF (405-409) \\
\hline 5 & PF3D7_1462800 & glyceraldehyde-3-phosphate dehydrogenase (GAPDH) & KLVSW (312-316) \\
\hline 6 & PF3D7_1343000 & phosphoethanolamine N-methyltransferase (PMT) & KIIF (103-106) \\
\hline
\end{tabular}

${ }^{a}$ Number of stained bands on SDS-PAGE

${ }^{\mathrm{b}}$ Annotations available on PlasmoDB database (v24)

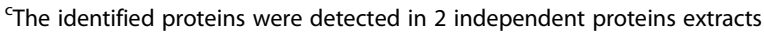

dSequences complying with consensus of RVxF and Fxx[RK]x[RK] were indicated

species. The low recovery by the affinity/mass spectrometry analysis could be attributed to several factors including the presence of very few free Pips in parasite extracts, their low solubility in buffers suitable for affinity column and/or the competition between Pips.

\section{Yeast two hybrid screening of a Pf CDNA library}

To further detect additional Pips in P. falciparum, a cDNA library was screened in a yeast two hybrid $(\mathrm{Y} 2 \mathrm{H})$ system using full-length PfPP1c as bait and clones growing on high stringency selection media to reduce the number of false positive clones. Five independent screens yielded 189 clones from a total of $3.3 \times 10^{6}$ clones screened. After sequencing, all clones showed open reading frames encoding Pf genes with 53 clones in frame with GAL4AD and 136 clones out of frame. Amino acid sequence comparison revealed that 8 proteins in frame with GAL4AD were also found among the out-of-frame clones. These data are in agreement with an earlier observation indicating that out-of-frame proteins could be considered as valid interactors in $\mathrm{Y} 2 \mathrm{H}$ screening [21] and with recent results suggesting that translational frameshift could be means for yeast to reduce the level of expression of exogenous proteins in order to grow on selective media. Indeed, this was observed with DHFR where most of isolated clones were not in frame with GAL4AD. In addition, this work showed that a reduction of growth rate of yeast was observed when the screening was carried out with DHFR fused in frame with GAL4AD [22]. Consequently, the GAL4AD in frame and out-of-frame clones were included in our analysis. In total, sequences identified from 189 clones represented 134 different proteins (Table 2) of which 27 were obtained more than once with 10 clones for PF3D7_1202600 and 9 clones for PF3D7_0919900 (Additional file 3: Table S3). Analysis of the sequences revealed that HSP70 (PF3D7_0818900) was isolated by Y2H screens, reinforcing the idea of its interaction with PfPP1 that we observed using parasite extracts and a PfPP1 affinity column. This supports the interaction of HSP70 with PP1 and suggests that besides its chaperone function it may control PP1 activity and/or regulate its binding with other partners. The $\mathrm{Y} 2 \mathrm{H}$ screens also identified the gene PF3D7_1020900 as a Pip. Its gene product shares $72 \%$ identity with a yeast ADP Ribosylation Factor (ARF1) which has been shown to interact with yeast PP1 [23] (Additional file 2: Table S2). Analysis of the Pf isolated fragment did not show the presence of known binding motifs to PP1. However the analysis of the full length sequence revealed the presence of $1 \mathrm{RVxF}$ motif, suggesting the presence of at least 2 PfPP1 potential binding motifs in this protein. Further, PF3D7_1103100 and PF3D7_1460700 showed 31 and $39 \%$ of identity with yeast RPP1B and RPL27A respectively (Additional file 2: Table $\mathrm{S} 2$ ), identified by different approaches as interactors of yeast PP1 [24, 25].

When the identified sequences were analyzed for the presence of known binding motifs to $\mathrm{PP} 1,30$ proteins share the RVxF binding motif and 20 contain the $\operatorname{Fxx}[R K] x[R K]$ motif, supporting the idea of their role as potential regulators of PP1. Indeed, it was reported that $70 \%$ of PP1 interacting proteins containing the RVxF motif are regulators of PP1 activity [26].

Further examination of $\mathrm{Y} 2 \mathrm{H}$ screening revealed that some identified clones correspond to different portions of the same protein (16 clones representing 7 proteins). For instance, PF3D7_1303800 interacts with PfPP1 through the protein portions 4987-5278, 6176-6407 (containing the $\operatorname{Fxx}[\mathrm{RK}] \mathrm{x}[\mathrm{RK}]$ motif) and 9165-9271 while PF3D7_0419900 binds PfPP1 via the portions 1857-1998 and 4414-4679 (Additional file 3: Table S3). For these proteins it seems that their binding to PfPP1 could take place through at least 2 to 3 regions, potentially involving novel binding motifs.

Among the isolated clones, 8 cDNAs representing 6 known kinases were identified as potential interacting 
Table 2 Pips identified by Yeast two-hybrid screening

\begin{tabular}{|c|c|c|c|c|}
\hline & $\begin{array}{l}\text { PlasmoDB Accession } \\
\text { number }^{\mathrm{a}}\end{array}$ & Name $^{a}$ & $\begin{array}{l}\text { Growth on selective plates } \\
\text { (number of isolated clones) }\end{array}$ & RVxF motifs ${ }^{c}$ \\
\hline \multirow[t]{32}{*}{ In frame genes } & PF3D7_0107600 & serine/threonine protein kinase, putative & $\mathrm{TDO} / \mathrm{A}(1)$ & \\
\hline & PF3D7_0220000 & liver stage antigen 3 (LSA3) & $\mathrm{QDO} / \mathrm{A}(2)$ & KKVRF \\
\hline & PF3D7_0418300 & conserved Plasmodium protein, unknown function & $\mathrm{QDO} / \mathrm{A}(1)$ & \\
\hline & PF3D7_0520800 & conserved Plasmodium protein, unknown function & $\mathrm{TDO} / \mathrm{A}(1)$ & \\
\hline & PF3D7_0520900 & S-adenosyl-L-homocysteine hydrolase (SAHH) & $\mathrm{TDO} / \mathrm{A}(1)$ & \\
\hline & PF3D7_0610100 & Pre-mRNA-splicing factor SLU7, putative (SLU7) & $\mathrm{TDO} / \mathrm{A}(1)$ & \\
\hline & PF3D7_0611800 & conserved Plasmodium protein, unknown function & $\mathrm{TDO} / \mathrm{A}(1)$ & \\
\hline & \multirow[t]{2}{*}{ PF3D7_0613800 } & \multirow[t]{2}{*}{ transcription factor with AP2 domain(s) (ApiAP2) } & QDO/A (1) & \multirow[t]{2}{*}{ RGVYF } \\
\hline & & & $\mathrm{TDO} / \mathrm{A}(1)$ & \\
\hline & PF3D7_0623100 & nuclear polyadenylated RNA-binding protein NAB2, putative & TDO/A (2) & \\
\hline & PF3D7_0718100 & exported serine/threonine protein kinase (EST) & $\mathrm{TDO} / \mathrm{A}(1)$ & \\
\hline & PF3D7_0720700 & phosphoinositide-binding protein, putative & $\mathrm{TDO} / \mathrm{A}(1)$ & \multirow[t]{5}{*}{ KIKF } \\
\hline & PF3D7_0724600 & protein kinase, putative & $\mathrm{TDO} / \mathrm{A}(1)$ & \\
\hline & PF3D7_0803400 & DNA repair protein rad54, putative & QDO/A (1) & \\
\hline & PF3D7_0816600 & ClpB protein, putative (ClpB1) & TDO/A (1) & \\
\hline & PF3D7_0917900 & heat shock protein 70 (HSP70-2) & $\mathrm{TDO} / \mathrm{A}(1)$ & \\
\hline & PF3D7_0919900 & regulator of chromosome condensation, putative & QDO/A (8) & \multirow[t]{2}{*}{ KSVSF } \\
\hline & PF3D7_1008000 & histone deacetylase 2 (HDA2) & $\mathrm{TDO} / \mathrm{A}(1)$ & \\
\hline & PF3D7_1008100 & conserved Plasmodium protein, unknown function & $\mathrm{TDO} / \mathrm{A}(1)$ & \multirow[t]{2}{*}{ KSVSF } \\
\hline & PF3D7_1020900 & ADP-ribosylation factor (ARF1) & $\mathrm{TDO} / \mathrm{A}(1)$ & \\
\hline & PF3D7_1031600 & conserved Plasmodium protein, unknown function (GEXP15) & QDO/A (3) & \multirow[t]{3}{*}{ KKVQF } \\
\hline & PF3D7_1105100 & histone $\mathrm{H} 2 \mathrm{~B}(\mathrm{H} 2 \mathrm{~B})$ & $\mathrm{TDO} / \mathrm{A}(1)$ & \\
\hline & PF3D7_1130700 & structural maintenance of chromosome protein, putative & TDO/A (2) & \\
\hline & PF3D7_1202600 & conserved protein, unknown function & QDO/A (10) & \multirow[t]{5}{*}{$\begin{array}{l}\text { KNVTF/KCVSF/ } \\
\text { KQVTF/RTVSF/ } \\
\text { KKVTF/ } \\
\text { KSVSF/KKVTF }\end{array}$} \\
\hline & PF3D7_1205500 & zinc finger protein, putative & $\mathrm{TDO} / \mathrm{A}(1)$ & \\
\hline & PF3D7_1228600 & merozoite surface protein 9 (MSP9) & $\mathrm{TDO} / \mathrm{A}(1)$ & \\
\hline & PF3D7_1229600 & conserved Plasmodium protein, unknown function & TDO/A (1) & \\
\hline & PF3D7_1303800 & conserved Plasmodium protein, unknown function & TDO/A (1) & \\
\hline & PF3D7_1317600 & conserved Plasmodium protein, unknown function & TDO/A (1) & \multirow[t]{2}{*}{ KYIYF } \\
\hline & PF3D7_1325800 & conserved Plasmodium protein, unknown function & $\mathrm{TDO} / \mathrm{A}(1)$ & \\
\hline & PF3D7_1346100 & protein transport protein SEC61 subunit alpha (SEC61) & $\mathrm{TDO} / \mathrm{A}(1)$ & \multirow[t]{2}{*}{ KGIEF } \\
\hline & PF3D7_1358200 & conserved Plasmodium protein, unknown function & $\mathrm{TDO} / \mathrm{A}(1)$ & \\
\hline \multirow{9}{*}{$\begin{array}{l}\text { Out of frame } \\
\text { genes }\end{array}$} & mal_mito_2 & cytochrome c oxidase subunit 1 (COX1) & $\mathrm{TDO} / \mathrm{A}(2)$ & \\
\hline & PF3D7_0110200 & FAD-linked sulfhydryl oxidase ERV1, putative (ERV1) & TDO/A (1) & \multirow[t]{8}{*}{ KINF } \\
\hline & PF3D7_0202400 & conserved Plasmodium protein, unknown function & $\mathrm{TDO} / \mathrm{A}(1)$ & \\
\hline & PF3D7_0205700.1 & conserved Plasmodium protein, unknown function & $\mathrm{TDO} / \mathrm{A}(1)$ & \\
\hline & PF3D7_0207100 & conserved Plasmodium protein, unknown function & $\mathrm{TDO} / \mathrm{A}(1)$ & \\
\hline & PF3D7_0207500 & serine repeat antigen 6 (SERA6) & $\mathrm{TDO} / \mathrm{A}(1)$ & \\
\hline & PF3D7_0307700 & conserved Plasmodium protein, unknown function & $\mathrm{TDO} / \mathrm{A}(1)$ & \\
\hline & PF3D7_0310400 & parasite-infected erythrocyte surface protein (PIESP1) & $\mathrm{TDO} / \mathrm{A}(1)$ & \\
\hline & PF3D7_0312800 & $60 S$ ribosomal protein $L 26$, putative & $\mathrm{TDO} / \mathrm{A}(1)$ & \\
\hline
\end{tabular}


Table 2 Pips identified by Yeast two-hybrid screening (Continued)

\begin{tabular}{|c|c|c|c|}
\hline PF3D7_0317300 & conserved Plasmodium protein, unknown function & $\mathrm{TDO} / \mathrm{A}(1)$ & \\
\hline PF3D7_0319500 & RNA binding protein, putative & $\mathrm{TDO} / \mathrm{A}(1)$ & \\
\hline PF3D7_0407700 & conserved Plasmodium protein, unknown function & $\mathrm{TDO} / \mathrm{A}(1)$ & RDIIF \\
\hline PF3D7_0417400 & conserved Plasmodium protein, unknown function & $\mathrm{TDO} / \mathrm{A}(1)$ & \\
\hline PF3D7_0418000 & conserved Plasmodium protein, unknown function & $\mathrm{TDO} / \mathrm{A}(2)$ & \\
\hline PF3D7_0418300 & conserved Plasmodium protein, unknown function & $\mathrm{TDO} / \mathrm{A}(2)$ & \\
\hline \multirow[t]{2}{*}{ PF3D7_0419900 } & phosphatidylinositol 4-kinase, putative & QDO/A (2) & \\
\hline & & $\mathrm{TDO} / \mathrm{A}(1)$ & \\
\hline PF3D7_0420000 & zinc finger protein, putative & $\mathrm{TDO} / \mathrm{A}(1)$ & \\
\hline PF3D7_0509200 & leucine-rich repeat protein (LRR2) & $\mathrm{QDO} / \mathrm{A}(1)$ & \\
\hline PF3D7_0516600 & translation initiation factor IF-2 & $\mathrm{TDO} / \mathrm{A}(1)$ & \\
\hline PF3D7_0516900 & 605 ribosomal protein L2 (RPL2) & $\mathrm{TDO} / \mathrm{A}(1)$ & KVIF \\
\hline PF3D7_0520800 & conserved Plasmodium protein, unknown function & QDO/A (1) & \\
\hline PF3D7_0520900 & S-adenosyl-L-homocysteine hydrolase (SAHH) & $\mathrm{TDO} / \mathrm{A}(1)$ & \\
\hline PF3D7_0525200 & conserved Plasmodium protein, unknown function & TDO/A (2) & $\mathrm{KIEF} / \mathrm{KDV} L F$ \\
\hline PF3D7_0530000 & conserved Plasmodium protein, unknown function & $\mathrm{TDO} / \mathrm{A}(1)$ & \\
\hline PF3D7_0532100 & early transcribed membrane protein 5 (ETRAMP5) & TDO/A (2) & \\
\hline PF3D7_0602000 & conserved Plasmodium protein, unknown function & $\mathrm{TDO} / \mathrm{A}(1)$ & \\
\hline PF3D7_0604500 & conserved Plasmodium protein, unknown function & $\mathrm{TDO} / \mathrm{A}(1)$ & \\
\hline PF3D7_0611700 & 605 ribosomal protein L39 (RPL39) & $\mathrm{TDO} / \mathrm{A}(2)$ & \\
\hline PF3D7_0613800 & transcription factor with AP2 domain(s) (ApiAP2) & $\mathrm{TDO} / \mathrm{A}(1)$ & \\
\hline PF3D7_0617200 & conserved Plasmodium protein, unknown function & $\mathrm{QDO} / \mathrm{A}(1)$ & KQIGF \\
\hline \multirow[t]{2}{*}{ PF3D7_0617800 } & histone $\mathrm{H} 2 \mathrm{~A}(\mathrm{H} 2 \mathrm{~A})$ & QDO/A (2) & \\
\hline & & $\mathrm{TDO} / \mathrm{A}(6)$ & \\
\hline PF3D7_0625300 & DNA polymerase 1 , putative & $\mathrm{TDO} / \mathrm{A}(1)$ & \\
\hline PF3D7_0709300 & Cg2 protein (CG2) & $\mathrm{TDO} / \mathrm{A}(1)$ & KVNF \\
\hline PF3D7_0719900 & $\begin{array}{l}\text { conserved Plasmodium membrane protein, unknown } \\
\text { function }\end{array}$ & $\mathrm{TDO} / \mathrm{A}(1)$ & \\
\hline \multirow[t]{2}{*}{ PF3D7_0721100 } & conserved Plasmodium protein, unknown function & QDO/A (1) & \\
\hline & & $\mathrm{TDO} / \mathrm{A}(1)$ & \\
\hline PF3D7_0725300 & conserved Plasmodium protein, unknown function & $\mathrm{TDO} / \mathrm{A}(1)$ & \\
\hline PF3D7_0806900 & conserved Plasmodium protein, unknown function & $\mathrm{QDO} / \mathrm{A}(1)$ & KNIGF/KIRW \\
\hline PF3D7_0809400 & conserved Plasmodium protein, unknown function & $\mathrm{TDO} / \mathrm{A}(1)$ & \\
\hline PF3D7_0811400 & conserved protein, unknown function & $\mathrm{TDO} / \mathrm{A}(1)$ & \\
\hline PF3D7_0813200 & CS domain protein, putative & $\mathrm{TDO} / \mathrm{A}(1)$ & \\
\hline PF3D7_0813300 & conserved Plasmodium protein, unknown function & $\mathrm{TDO} / \mathrm{A}(1)$ & \\
\hline PF3D7_0814000 & 605 ribosomal protein $\mathrm{L} 13-2$, putative & QDO/A (2) & RVNF \\
\hline PF3D7_0815800 & vacuolar sorting protein VPS9, putative & $\mathrm{TDO} / \mathrm{A}(1)$ & \\
\hline PF3D7_0818000 & conserved protein, unknown function & $\mathrm{TDO} / \mathrm{A}(1)$ & \\
\hline PF3D7_0818900 & heat shock protein 70 (HSP70) & $\mathrm{TDO} / \mathrm{A}(1)$ & \\
\hline PF3D7_0831700 & heat shock protein 70, putative (HSP70-x) & QDO/A (1) & \\
\hline PF3D7_0904000 & GTPase-activating protein, putative & $\mathrm{TDO} / \mathrm{A}(1)$ & \\
\hline PF3D7_0919900 & regulator of chromosome condensation, putative & $\mathrm{TDO} / \mathrm{A}(1)$ & \\
\hline PF3D7_0921700 & conserved Plasmodium protein, unknown function & $\mathrm{QDO} / \mathrm{A}(1)$ & \\
\hline PF3D7_0924100 & conserved Plasmodium protein, unknown function & $\mathrm{TDO} / \mathrm{A}(1)$ & \\
\hline
\end{tabular}


Table 2 Pips identified by Yeast two-hybrid screening (Continued)

\begin{tabular}{|c|c|c|c|}
\hline PF3D7_0932100 & protein MAM3, putative & $\mathrm{TDO} / \mathrm{A}(1)$ & \\
\hline PF3D7_0933300 & conserved Plasmodium protein, unknown function & $\mathrm{TDO} / \mathrm{A}(1)$ & \\
\hline PF3D7_1020200 & conserved Plasmodium protein, unknown function & $\mathrm{TDO} / \mathrm{A}(1)$ & KNVFF \\
\hline PF3D7_1023400 & HORMA domain protein, putative & QDO/A (1) & \\
\hline PF3D7_1029900 & conserved Plasmodium protein, unknown function & $\mathrm{TDO} / \mathrm{A}(1)$ & \\
\hline PF3D7_1032000 & ribosome maturation factor RimM, putative (RimM) & $\mathrm{TDO} / \mathrm{A}(1)$ & \\
\hline PF3D7_1103100 & 605 acidic ribosomal protein P1, putative (RPP1) & $\mathrm{TDO} / \mathrm{A}(1)$ & \\
\hline PF3D7_1105100 & histone $\mathrm{H} 2 \mathrm{~B}(\mathrm{H} 2 \mathrm{~B})$ & $\mathrm{TDO} / \mathrm{A}(2)$ & \\
\hline PF3D7_1107300 & $\begin{array}{l}\text { polyadenylate-binding protein-interacting protein 1, putative } \\
\text { (PAIP1) }\end{array}$ & TDO/A (1) & \\
\hline PF3D7_1108600 & $\begin{array}{l}\text { endoplasmic reticulum-resident calcium binding protein } \\
\text { (ERC) }\end{array}$ & TDO/A (1) & KVYF \\
\hline PF3D7_1116200.1 & pyridoxine biosynthesis protein PDX2 (PDX2) & $\mathrm{QDO} / \mathrm{A}(1)$ & \\
\hline PF3D7_1117700 & GTP-binding nuclear protein ran/tc4 (RAN) & $\mathrm{QDO} / \mathrm{A}(1)$ & RQIQF \\
\hline PF3D7_1121600 & circumsporozoite-related antigen,exported protein 1 (EXP1) & $\mathrm{TDO} / \mathrm{A}(1)$ & \\
\hline PF3D7_1127900 & conserved Plasmodium protein, unknown function & $\mathrm{TDO} / \mathrm{A}(1)$ & \\
\hline PF3D7_1141400 & $\begin{array}{l}\text { phosphatidylinositol N-acetylglucosaminyltransferase subunit } \\
\text { H, putative (PIGH) }\end{array}$ & $\mathrm{TDO} / \mathrm{A}(1)$ & \\
\hline PF3D7_1149000 & antigen 332, DBL-like protein (Pf332) & $\mathrm{TDO} / \mathrm{A}(1)$ & KIIW \\
\hline PF3D7_1206800 & conserved Plasmodium protein, unknown function & QDO/A (1) & \\
\hline PF3D7_1210600 & conserved Plasmodium protein, unknown function & $\mathrm{QDO} / \mathrm{A}(1)$ & \\
\hline PF3D7_1211200 & conserved Plasmodium protein, unknown function & $\mathrm{TDO} / \mathrm{A}(1)$ & $\begin{array}{l}\text { KVKF/KRINF/ } \\
\text { KYIEF }\end{array}$ \\
\hline PF3D7_1214100 & GPI ethanolamine phosphate transferase 3, putative (PIGO) & $\mathrm{TDO} / \mathrm{A}(1)$ & \\
\hline PF3D7_1222300 & endoplasmin, putative (GRP94) & $\mathrm{TDO} / \mathrm{A}(1)$ & \\
\hline PF3D7_1224000 & GTP cyclohydrolase I (GCH1) & $\mathrm{TDO} / \mathrm{A}(1)$ & \\
\hline PF3D7_1227000 & conserved Plasmodium protein, unknown function & $\mathrm{TDO} / \mathrm{A}(2)$ & \\
\hline PF3D7_1227700 & conserved Plasmodium protein, unknown function & $\mathrm{TDO} / \mathrm{A}(1)$ & \\
\hline \multirow[t]{2}{*}{ PF3D7_1228600 } & merozoite surface protein 9 (MSP9) & $\mathrm{QDO} / \mathrm{A}(1)$ & \\
\hline & & TDO/A (1) & \\
\hline \multirow[t]{2}{*}{ PF3D7_1229400 } & macrophage migration inhibitory factor (MIF) & $\mathrm{QDO} / \mathrm{A}(1)$ & \\
\hline & & $\mathrm{TDO} / \mathrm{A}(1)$ & \\
\hline PF3D7_1231600 & $\begin{array}{l}\text { pre-mRNA-splicing factor ATP-dependent RNA helicase PRP2, } \\
\text { putative (PRP2) }\end{array}$ & TDO/A (1) & \\
\hline PF3D7_1234600 & conserved Plasmodium protein, unknown function & TDO/A (1) & \\
\hline PF3D7_1234900 & conserved Plasmodium protein, unknown function & $\mathrm{TDO} / \mathrm{A}(1)$ & \\
\hline PF3D7_1240600 & erythrocyte membrane protein 1, PfEMP1 (VAR) & $\mathrm{TDO} / \mathrm{A}(1)$ & \\
\hline PF3D7_1249800 & THO complex subunit 2, putative ( $\mathrm{THO} 2)$ & $\mathrm{TDO} / \mathrm{A}(1)$ & \\
\hline PF3D7_1303800 & conserved Plasmodium protein, unknown function & TDO/A (2) & \\
\hline PF3D7_1306400 & $26 \mathrm{~S}$ protease regulatory subunit 10B, putative (RPT4) & $\mathrm{TDO} / \mathrm{A}(1)$ & \\
\hline PF3D7_1308400 & conserved Plasmodium protein, unknown function & $\mathrm{QDO} / \mathrm{A}(1)$ & RRVLF \\
\hline \multirow[t]{2}{*}{ PF3D7_1308800 } & tyrosine recombinase (INT) & $\mathrm{QDO} / \mathrm{A}(1)$ & KYIKF \\
\hline & & TDO/A (1) & \\
\hline PF3D7_1316100 & inositol polyphosphate kinase, putative (IPK2) & $\mathrm{TDO} / \mathrm{A}(1)$ & \\
\hline PF3D7_1324800 & $\begin{array}{l}\text { dihydrofolate synthase/folylpolyglutamate synthase } \\
\text { (DHFS-FPGS) }\end{array}$ & QDO/A (1) & \\
\hline PF3D7_1326600 & conserved Plasmodium protein, unknown function & QDO/A (2) & \\
\hline
\end{tabular}


Table 2 Pips identified by Yeast two-hybrid screening (Continued)

\begin{tabular}{|c|c|c|c|}
\hline PF3D7_1336600 & conserved Plasmodium protein, unknown function & $\mathrm{TDO} / \mathrm{A}(1)$ & \\
\hline PF3D7_1342300 & tetratricopeptide repeat family protein, putative & TDO/A (1) & \\
\hline PF3D7_1342900 & transcription factor with AP2 domain(s) (ApiAP2) & $\mathrm{TDO} / \mathrm{A}(1)$ & \\
\hline PF3D7_1346400 & conserved Plasmodium protein, unknown function & $\mathrm{TDO} / \mathrm{A}(1)$ & \\
\hline PF3D7_1348400 & $\begin{array}{l}\text { conserved Plasmodium membrane protein, unknown } \\
\text { function }\end{array}$ & $\mathrm{TDO} / \mathrm{A}(1)$ & \\
\hline PF3D7_1351200 & conserved Plasmodium protein, unknown function & $\mathrm{TDO} / \mathrm{A}(1)$ & KYVNW \\
\hline PF3D7_1356900 & protein kinase 5 (PK5) & $\mathrm{TDO} / \mathrm{A}(1)$ & \\
\hline PF3D7_1357400 & conserved Plasmodium protein, unknown function & QDO/A (1) & KSIRF \\
\hline PF3D7_1360700 & E3 SUMO-protein ligase PIAS, putative (PIAS) & QDO/A (1) & KKVLW \\
\hline PF3D7_1361200 & conserved Plasmodium protein, unknown function & $\mathrm{TDO} / \mathrm{A}(1)$ & \\
\hline PF3D7_1366400 & rhoptry protein (Rhop148) & $\mathrm{TDO} / \mathrm{A}(1)$ & KILF \\
\hline PF3D7_1417600 & conserved Plasmodium protein, unknown function & $\mathrm{TDO} / \mathrm{A}(1)$ & \\
\hline PF3D7_1423700 & conserved Plasmodium protein, unknown function & TDO/A (1) & \\
\hline PF3D7_1444300 & $\begin{array}{l}\text { 1-acyl-sn-glycerol-3-phosphate acyltransferase, putative } \\
\text { (LPAAT) }\end{array}$ & $\mathrm{TDO} / \mathrm{A}(1)$ & \\
\hline PF3D7_1456500 & conserved Plasmodium protein, unknown function & QDO/A (2) & \\
\hline PF3D7_1457000 & signal peptide peptidase (SPP) & QDO/A (1) & \\
\hline PF3D7_1460500 & conserved Plasmodium protein, unknown function & $\mathrm{TDO} / \mathrm{A}(1)$ & KVDF/KTVSF \\
\hline PF3D7_1460700 & 605 ribosomal protein L27 (RPL27) & $\mathrm{TDO} / \mathrm{A}(1)$ & \\
\hline PF3D7_1464500 & $\begin{array}{l}\text { conserved Plasmodium membrane protein, unknown } \\
\text { function }\end{array}$ & $\mathrm{TDO} / \mathrm{A}(1)$ & \\
\hline PF3D7_1465900 & 40 S ribosomal protein $\$ 3$, putative & TDO/A (1) & \\
\hline PF3D7_1466300 & 265 proteasome regulatory subunit RPN2, putative (RPN2) & $\mathrm{TDO} / \mathrm{A}(1)$ & \\
\hline PF3D7_1470800 & conserved Plasmodium protein, unknown function & $\mathrm{TDO} / \mathrm{A}(1)$ & \\
\hline PF3D7_1471900 & conserved Plasmodium protein, unknown function & $\mathrm{TDO} / \mathrm{A}(1)$ & KIIEF \\
\hline
\end{tabular}

${ }^{\mathrm{a} A n n o t a t i o n s ~ a v a i l a b l e ~ o n ~ P l a s m o D B ~ d a t a b a s e ~(v 24) ~}$

${ }^{b}$ Selection medium used for the growth of isolated yeast clones were indicated. Numbers indicate the count of isolated clones. TDO/A Triple dropout supplemented with Aureobasidin A, QDO/A Quadruple dropout supplemented with Aureobasidin A

'The presence and the sequence of RVxF binding motifs were indicated

${ }^{\mathrm{d}}$ Shared proteins isolated by affinity purification and $\mathrm{Y} 2 \mathrm{H}$ screening

proteins for PP1 but none of the fragments contains any known binding motifs. This supports the idea that these kinases encompass new PP1-binding region/motifs. Examination of the full length proteins of these 6 kinases showed the presence of at least one binding motif (Additional file 3: Table S3). It would be important to check whether these motifs are also involved in interaction with PP1. Taken together, it could be speculated that these kinases could be direct substrates and/ or regulators of PfPP1 and vice versa.

In addition to the interaction of PfPP1 and kinases, PfH2A, PfH2B and Pf Histone deacetylase 2 (PfHDA2) have been identified as Pips. All of these proteins are associated with nucleosome modifications and could direct the control of gene expression. Previous studies showed that the phosphorylation marks of $\mathrm{H} 2 \mathrm{~A}$ and $\mathrm{H} 2 \mathrm{~B}$ are detected along with lysine acetylation [27, 28]. The interaction of H2A and PP1 has also been reported in yeast
[24, 29] (Additional file 2: Table S2). Taken together, these observations suggest a potential role and/or a control of the PP1 network in the marks of histones to govern diverse nuclear actions in $P$. falciparum.

\section{Identification of Pips by in silico screening of the Pf genome}

PP1 partners have been identified by biochemical and $\mathrm{Y} 2 \mathrm{H}$ approaches, both of which can have their limitations: the quality and quantity of protein preparations, or the incapacity of yeast to produce Pf proteins (or proteins toxic for the growth of yeast). In order to further examine the presence of Pips genes in Pf, we used an extended $\mathrm{RVxF}$ consensus sequence mentioned in Materials and Methods. The choice of this extended consensus sequence, referred thereafter as $\mathrm{RVxF}^{\mathrm{ext}}$, was based on previous studies indicating its high specificity $[30,31]$. The first consensus sequence defined by 
Wakula et al. [12] was not used in this study because it is less restrictive and it occurs randomly in $\sim 25 \%$ of all proteins [30]. The bioinformatics analysis was performed with ORFs present in PlasmoDB (v24). This screening showed the presence of $55 \mathrm{RVxF}^{\text {ext }}$ motif containing proteins in $P$. falciparum of which 5 proteins contain at least 2 motifs (Table 3). Two $\mathrm{RVxF}^{\text {ext }}$ containing proteins were excluded as one corresponds to a pseudogene and the second is annotated twice in PlasmoDB. Interestingly, among the 55 in silico Pips, 42 exhibit at least one additional binding motif to PP1 (SILK and/or Fxx[RK]x[RK]) (Additional file 4: Table S4). In addition, 8 proteins identified in silico were also isolated by $\mathrm{Y} 2 \mathrm{H}$ screening while 1 protein was common between the affinity/MS-MS approach and $\mathrm{Y} 2 \mathrm{H}$ screening (Fig. 1). Among the 8 shared proteins, 6 clones identified by $\mathrm{Y} 2 \mathrm{H}$ screening followed the $\mathrm{RVxF}^{\text {ext }}$ consensus sequence. Further, homologs to 2 potential in silico PfPips (PF3D7_1107700, PF3D7_1220100) have been shown to interact with PP1 in S. cerevisiae (Additional file 2: Table S2) [23, 32, 33]. The in silico screening applied in this work cannot include PfLRR1 and Pf Inhibitors 2 and 3, known to bind and to regulate PfPP1 activity. Indeed, PfLRR1 binds PP1 through LRR motifs, however PfI2 and PfI3 encompass the short RVxF motif.

\section{Validation of interaction of Pips identified}

All interactors identified by the above approaches could be capable of binding directly to PfPP1. To explore this further, we decided to investigate the physical interaction of PfPP1 with some of PfPips produced as recombinant proteins. To this end, a binding assay with purified Histagged fusion Pips in E. coli and biotin labeled PfPP1 was used. This approach has already been used and validated using recombinant proteins of known partners of PfPP1 or derived peptides from binding motifs [17]. PfI2 and PfI3, previously described to interact with PfPP1, were used as positive controls. A total of 37 PfPips were successfully produced as recombinant proteins in $E$. coli and purified out of 68 candidates tested and corresponding to 66 different Pips.

In the case of the Pips identified by PfPP1 affinity column, 5 proteins were produced out of 6 . Binding data presented in Fig. 2a showed that biotin-PfPP1 binds to the 5 proteins tested. These data likely suggests that the identified Pips are direct interactors of PfPP1.

Next, we searched to check the direct interactions of Pips identified by $\mathrm{Y} 2 \mathrm{H}$ screening and PfPP1. Fifteen recombinant PfPips were produced out of 30 cloned cDNAs tested (Additional file 5: Figure S1, Additional file 6: Table S5). The failure for the production of some proteins could be due to the lack of expression and/or to the toxicity for bacteria. For the binding with $\mathrm{H} 2 \mathrm{~A}$ and $\mathrm{H} 2 \mathrm{~B}$, commercially available human recombinant proteins were used as they showed 67 and $63 \%$ identity with $\mathrm{PfH} 2 \mathrm{~A}$ and $\mathrm{PfH} 2 \mathrm{~B}$ respectively (Additional file 7: Figure S2). As depicted in Fig. 2b, biotin-PfPP1 was able to bind to 14 recombinant proteins out of 17 tested. These data confirmed a direct interaction between PfPP1 and these Pips. Moreover, this binding assay showed that Pips with or without the RVxF motif can bind PfPP1 and confirmed that proteins which are out of frame of GAL4AD could be true Pips. However, under the same conditions, 3 proteins did not show significant binding when compared to BSA. The lack of binding is unlikely to be due to an absence of coating of purified protein to wells as the quality of coating was checked using an antiHis antibody (data not shown). It could be argued that these proteins are not direct partners of PfPP1 or their interaction may require additional partner(s) expressed by the yeast.

Finally, in order to examine the binding capacity of several in silico Pips identified by genome analysis, 32 fragments which correspond to 30 potential candidates were tested for protein production. The fragments were about 190 residues long with the $\mathrm{RVxF}^{\text {ext }}$ motif in the middle of the recombinant proteins (Additional file 5: Figure S1, Additional file 6: Table S5). The expression and purification were successful for only 17 proteins. Their ability to bind PP1 was then examined as described above. Significant interactions for 16 out of 17 proteins tested were observed (Fig. 2c). The lack of interaction of PfPP1 with PF3D7_0305500 could be attributed to the fact that its RVxF is not a valid binding motif. However, it is important to point out that 6 Pips identified by $\mathrm{Y} 2 \mathrm{H}$ and in silico screens (PF3D7_0220000, PF3D7_0610100, PF3D7_0919900, PF3D7_1008100, PF3D7_1031600 and PF3D7_1202600) were confirmed to interact with PfPP1 by ELISA (Fig. 2b and c), highlighting the accuracy of the $\mathrm{RVxF}$ consensus sequence used throughout this study.

To further explore the implication of the RVxF motifs in PfPP1 binding, 2 Pips identified by $\mathrm{Y} 2 \mathrm{H}$ screening and in silico analysis were mutated in their RVxF motifs and the corresponding recombinant proteins were produced. Results presented in Fig. 2d showed a significant decrease of the binding with PfPP1 (about $86 \%$ for PF3D7_0220000 and 70\% for PF3D7_0919900). This confirms that the RVxF motifs of these 2 Pips are the main contributors for binding to PfPP1. However, it could not be excluded that these interactions could involve secondary structures of the protein to stabilize and to lead to a functional complex. This could be attributed to the fact that the $\mathrm{RVxF}$ binding motif, in most regulators, is often present in intrinsically disordered regions and the protein could adopt a structure upon binding $[16,17]$.

The newly RVxF-containing PfPips were then used to reexamine the features of the $\mathrm{RVxF}$ motif and the nature 
Table 3 Pips identified by genome in silico analysis

\begin{tabular}{|c|c|c|}
\hline PlasmoDB Accession number ${ }^{a}$ & Name $^{a}$ & $\mathrm{RVXF}^{\mathrm{ext}}$ motifs $^{\mathrm{b}}$ \\
\hline PF3D7_0204600 & conserved Plasmodium protein, unknown function & RKSVRW \\
\hline PF3D7_0214400 & conserved Plasmodium protein, unknown function & KKKVTF \\
\hline PF3D7_0220000 & liver stage antigen 3 (LSA3) & KKKVRF \\
\hline PF3D7_0304300 & conserved Plasmodium protein, unknown function & KKKVTF \\
\hline PF3D7_0305500 & conserved Plasmodium protein, unknown function & KRNVSF/KRSVHF \\
\hline PF3D7_0323300 & conserved protein, unknown function & KKSVSF \\
\hline PF3D7_0404700 & dipeptidyl aminopeptidase 3 (DPAP3) & RKNVTF \\
\hline PF3D7_0407300 & transcription factor, putative & KKKVHF \\
\hline PF3D7_0407700 & conserved Plasmodium protein, unknown function & KKKVSW \\
\hline PF3D7_0416900 & conserved Plasmodium protein, unknown function & KRNVHF \\
\hline PF3D7_0503000 & 50 S ribosomal protein $\mathrm{L} 28$, apicoplast, putative & RKNVRF \\
\hline PF3D7_0513600 & deoxyribodipyrimidine photo-lyase, putative & KKQVSF \\
\hline PF3D7_0526500 & conserved Plasmodium protein, unknown function & KKCVHF \\
\hline PF3D7_0526600 & conserved Plasmodium protein, unknown function & KKKVTF \\
\hline PF3D7_0610100 & pre-mRNA-splicing factor SLU7, putative (SLU7) & KKKVNF \\
\hline PF3D7_0628100 & HECT-domain (ubiquitin-transferase), putative & RKSVKF/KKSVTF \\
\hline PF3D7_0713900 & conserved Plasmodium protein, unknown function & KKNVNF \\
\hline PF3D7_0717800 & conserved Plasmodium protein, unknown function & KRSVSW \\
\hline PF3D7_0723800 & conserved Plasmodium protein, unknown function & KKSVQF \\
\hline PF3D7_0727500 & conserved Plasmodium protein, unknown function & KKCVSF \\
\hline PF3D7_0804500 & conserved Plasmodium membrane protein, unknown function & KKNVHF \\
\hline PF3D7_0913600 & conserved Plasmodium protein, unknown function & KKMVHF \\
\hline PF3D7_0917500 & conserved Plasmodium protein, unknown function & RKAVQF \\
\hline PF3D7_0919900 & regulator of chromosome condensation, putative & KKSVSF \\
\hline PF3D7_0922800 & conserved Plasmodium protein, unknown function & KKNVCF \\
\hline PF3D7_0930100 & conserved Plasmodium protein, unknown function & KKTVHF \\
\hline PF3D7_1002900 & conserved Plasmodium protein, unknown function & KRNVNF \\
\hline PF3D7_1003700 & conserved Plasmodium protein, unknown function & KRKVKF \\
\hline PF3D7_1008100 & conserved Plasmodium protein, unknown function & RKSVSF \\
\hline PF3D7_1020600 & conserved Plasmodium membrane protein, unknown function & KKKVNW \\
\hline PF3D7_1022200 & conserved Plasmodium membrane protein, unknown function & KKWRF \\
\hline PF3D7_1029400 & conserved Plasmodium protein, unknown function & KKNVSF \\
\hline PF3D7_1031600 & conserved Plasmodium protein, unknown function (GEXP15) & KKKVQF \\
\hline PF3D7_1107700 & pescadillo-like protein (PES) & KKKVTW \\
\hline PF3D7_1106800 & protein kinase, putative & KKKVSF \\
\hline PF3D7_1109100 & conserved Plasmodium protein, unknown function & RRKVSF \\
\hline PF3D7_1113700 & glyoxalase I (Glol) & KKNVKF \\
\hline PF3D7_1128000.1 & conserved Plasmodium protein, unknown function & KKNVTF \\
\hline PF3D7_1139700 & adrenodoxin reductase, putative & RKKVHF \\
\hline PF3D7_1200100 & erythrocyte membrane protein 1, PfEMP1 (VAR) & RKTVRF \\
\hline PF3D7_1202600 & conserved protein, unknown function & $\begin{array}{l}\text { KKNVTF/KKQVTF/ } \\
\text { KRTVSF/KKSVSF/ } \\
\text { KKTVSF/KKSVSF/KKNVSF }\end{array}$ \\
\hline PF3D7_1220100 & pre-mRNA splicing factor, putative & KKMVNF \\
\hline PF3D7_1234700 & CPW-WPC family protein & KKSVSF \\
\hline
\end{tabular}


Table 3 Pips identified by genome in silico analysis (Continued)

\begin{tabular}{lll}
\hline PF3D7_1238500 & conserved Plasmodium protein, unknown function & KKKVHF \\
PF3D7_1244200 & transcription factor Tfb2, putative & RKSVHF \\
PF3D7_1244500 & conserved Plasmodium protein, unknown function & RRKVNF \\
PF3D7_1322100 & variant-silencing SET protein (SETVs) & KRNVSF \\
PF3D7_1364300 & pre-mRNA-splicing factor ATP-dependent RNA helicase PRP16 (PRP16) & RKMVQF \\
PF3D7_1366300 & conserved Plasmodium protein, unknown function & KKWKF/KKKVQF \\
PF3D7_1367500 & NADH-cytochrome b5 reductase, putative & KKHVHF \\
PF3D7_1406200 & conserved Plasmodium protein, unknown function & KKMVSF \\
PF3D7_1411500 & conserved Plasmodium protein, unknown function & KKQVSF/KKKVSF \\
PF3D7_1413000 & conserved Plasmodium protein, unknown function & KKNVQF \\
PF3D7_1417300 & cysteine protease ATG4, putative (ATG4) & KKKVRF \\
PF3D7_1460500 & conserved Plasmodium protein, unknown function & RKTVSF \\
\hline
\end{tabular}

${ }^{\mathrm{a}}$ Annotations from PlasmoDB database (v24)

${ }^{\mathrm{b}} \mathrm{The} \mathrm{RVxF}^{\mathrm{ext}}$ binding motifs corresponding to the [KR][KR][ACHKMNQRSTV]V[CHKNQRST][FW] consensus sequence were indicated

'Shared proteins isolated by $\mathrm{Y} 2 \mathrm{H}$ and in silico screenings

of the flanking amino acids in P. falciparum. The accepted motif exhibits the sequence $\left[K_{52} R_{13}\right]\left[K_{55} R_{10}\right]\left[K_{19} N_{15} S_{13} T_{5}\right]$ $\mathrm{V}\left[\mathrm{S}_{22} \mathrm{H}_{11} \mathrm{~T}_{9} \mathrm{R}_{6} \mathrm{Q}_{6} \mathrm{~N}_{6}\right]\left[\mathrm{F}_{60} \mathrm{~W}_{5}\right]$ (Additional file 8: Figure S3). Interestingly, the amino acids between $\mathrm{V}$ and $\mathrm{F} / \mathrm{W}$ are enriched by $\mathrm{S}$ and $\mathrm{H}(\sim 50 \%)$. At the $\mathrm{N}$-terminal positions of the $\operatorname{RVxF}(-1$, and -2$)$, the most conserved amino acid is the $\mathrm{K}$ residue. We have also found a high frequency of $\mathrm{L}$ residue at -2 . Based on these data, the $\mathrm{RVxF}$ consensus sequence for PfPips could be extended and refined as

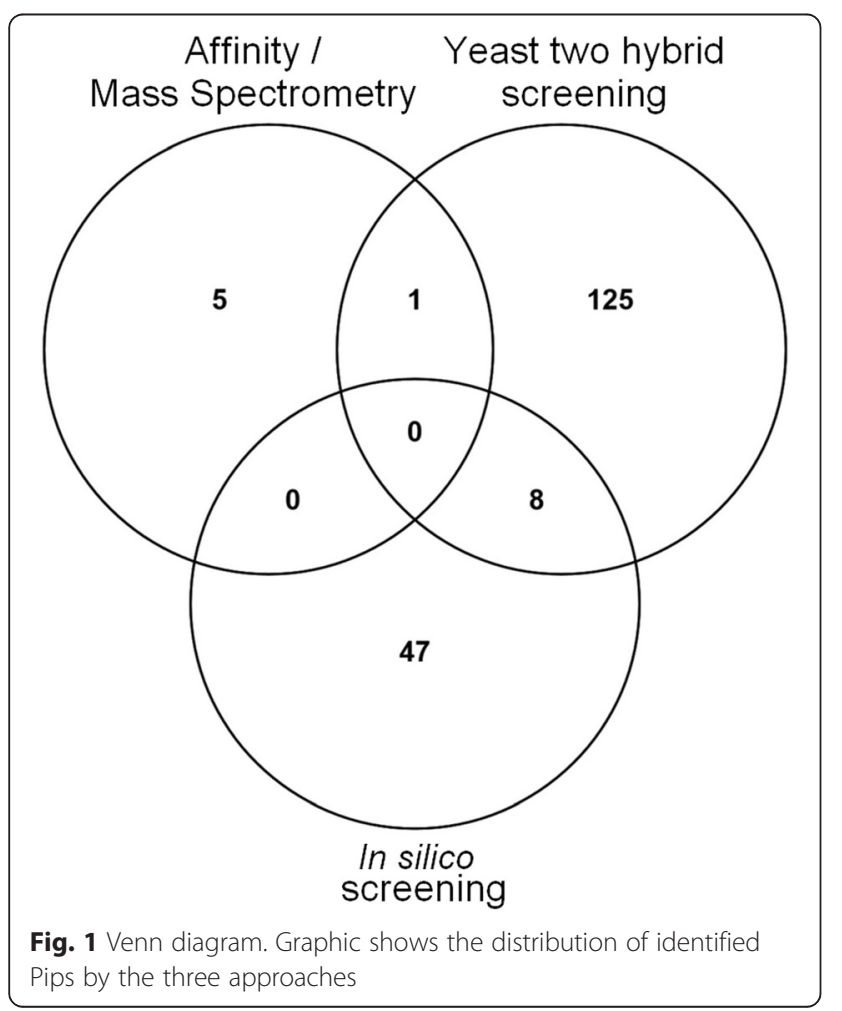

$\left[\mathrm{K}_{13} \mathrm{~L}_{12} \mathrm{I}_{7} \mathrm{~V}_{6}\right]\left[\mathrm{K}_{18} \mathrm{~N}_{8} \mathrm{I}_{8} \mathrm{R}_{5}\right]\left[\mathrm{K}_{52} \mathrm{R}_{13}\right]\left[\mathrm{K}_{55} \mathrm{R}_{10}\right]\left[\mathrm{K}_{19} \mathrm{~N}_{15} \mathrm{~S}_{13} \mathrm{~T}_{5}\right] \mathrm{V}$ $\left[\mathrm{S}_{22} \mathrm{H}_{11} \mathrm{~T}_{9} \mathrm{R}_{6} \mathrm{Q}_{6} \mathrm{~N}_{6}\right]\left[\mathrm{F}_{60} \mathrm{~W}_{5}\right]$.

\section{PfPP1 interaction networks}

The identification in this study of 186 new Pips provides new insights on the functional diversity of PfPP1 functions. Among the 186 identified proteins, 108 (58 \%) have unknown function. For the 78 remaining proteins, the most abundant proteins correspond to metabolism, DNA maintenance, translation and phosphorylation processes (Fig. 3).

Based on an earlier published $P$. falciparum interactome [34] and on the identified PP1 interacting proteins reported in this work, we were able to establish three networks where several Pips could be involved. The transcription and DNA maintenance network illustrated in Figure S4A (Additional file 9) contained 9 direct Pips (white circles) detected by the different approaches described above and 4 connecting proteins (gray circles). The folding/proteolysis network involved 8 direct Pips and 2 connecting proteins (Additional file 9: Figure S4B). The pathogenicity network comprised 18 direct Pips and 16 connecting proteins (Fig. 4). In the latter network, 2 homologs of direct Pips in P. berghei (PBANKA_0408500 homolog to PF3D7_0310400 and PBANKA_0926700 homolog to PF3D7_1121600) have been shown to be essential for parasite survival as no viable $\mathrm{KO}$ parasites can be obtained $[35,36]$. It is worthy of note that PF3D7_1023900, a connecting protein, contains a region of about 700 amino acids with $40 \%$ identity with a yeast protein (YER164W) which has been shown to interact with yeast PP1 [23]. Its homolog in P. berghei (PBANKA_050810) has been shown to be essential for parasite survival [35]. The network analysis raises the possibility that new Pips 

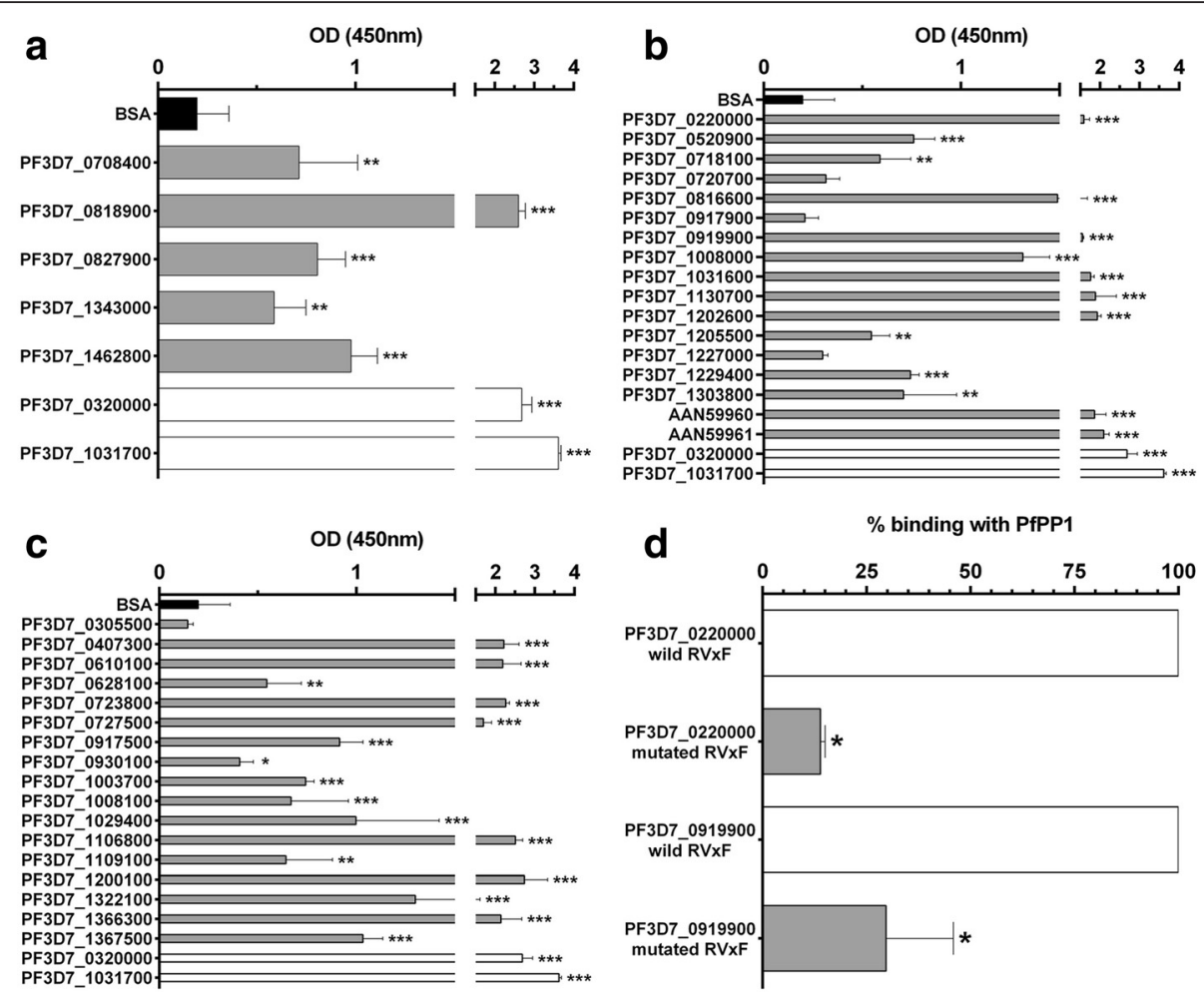

Fig. 2 Direct interaction of Pips to PfPP1. The binding capacity of recombinant Pips (25pmol/well) to biotin-PfPP1 (4pmol/well) was measured using an ELISA-based assay. a represents the binding of recombinant Pips identified by PP1-affinity column (gray bars). Pfl2 (PF3D7_0320000) and PfI3 (PF3D7_1031700) were used as positive controls (white bars) and BSA was used as negative control (black bars). $\mathbf{b}$ represents the binding of Pips identified by Y2H screening (gray bars). AAN59960 and AAN59961 are human H2A and H2B proteins respectively which present high identity with PfH2A (PF3D7_0617800) and PfH2B (PF3D7_1105100). $\mathbf{c}$ represents the Pips identified by genome in silico analysis (gray bars). $\mathbf{d}$ contribution of the RVxF motifs to the binding of PF3D7_0220000 and PF3D7_0919900 to PfPP1 (gray bars). The interaction of PfPP1 to wild proteins was considered at $100 \%$ binding. Results are presented as mean \pm SD of 2 independent experiments preformed in duplicate. ${ }^{*} p<0.05,{ }^{* *} p<0.01$ and ${ }^{* *} p<0.001$ (Mann-Whitney $U$ test), compared to the negative control

could play a role in pathogenicity, at least in part, through their interaction with and regulation of PfPP1. However, it cannot be excluded that these proteins could be also substrates of PfPP1.

\section{Conclusion}

The diversity of proteins identified by three different and complementary approaches suggests that PP1c has a wide interaction network which controls several aspects of parasite physiology. A total of 186 proteins were identified by these approaches. One protein was common to both $\mathrm{Y} 2 \mathrm{H}$ screening and PfPP1-affinity column approach and 8 proteins to $\mathrm{Y} 2 \mathrm{H}$ and in silico screenings. This provides experimental support to determine the contribution of the RVxF motif to PfPP1 binding when present in Pips, to identify new binding regions/motifs specific of Plasmodium and to explore the role of Pips as regulators, substrates or both. Further experiments need to be done to determine PfPP1 substrates, for instance by identifying the phosphoproteomes of Pf in vitro in the absence and presence of recombinant active PfPP1, and to evaluate whether the new Pips could be able to regulate PfPP1 activity. These future studies will help to better elucidate PP1 signaling in Plasmodium and to increase and improve the choice of parasite targets for drug design.

\section{Methods}

\section{Affinity purification of Pips}

For affinity purification, $10 \mathrm{mg}$ of PfPP1 recombinant protein (produced as previously described [17]) were covalently coupled to $0.5 \mathrm{ml}$ of $\mathrm{CNBr}$-activated Sepharose $4 \mathrm{~B}$ according to the supplier's instructions (Sigma). The coupling efficiency was $>90 \%$. Before use, PP1 beads were submitted to 3 wash cycles with $3 \mathrm{M} \mathrm{NaSCN}$ and PBS. Ten mg of total soluble parasite extract (prepared as previously described [17]) were precleared on $2 \mathrm{ml}$ of activated sepharose beads blocked with ethanolamine. The precleared extract recovered by centrifugation was filtered, divided in 2 equal volumes and incubated with 


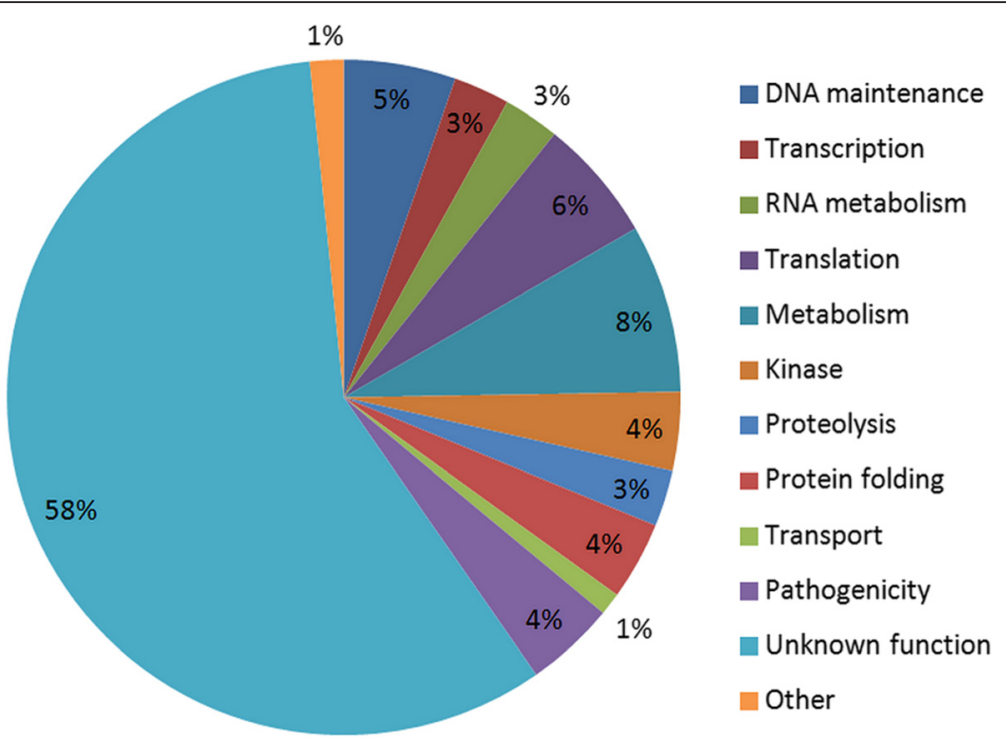

Fig. 3 Pie chart of biological functions of Pips. A total of 186 proteins are classified in 12 different biological functions based on confirmed or putative functions indicated in PlasmoDB and shown in our pie chart

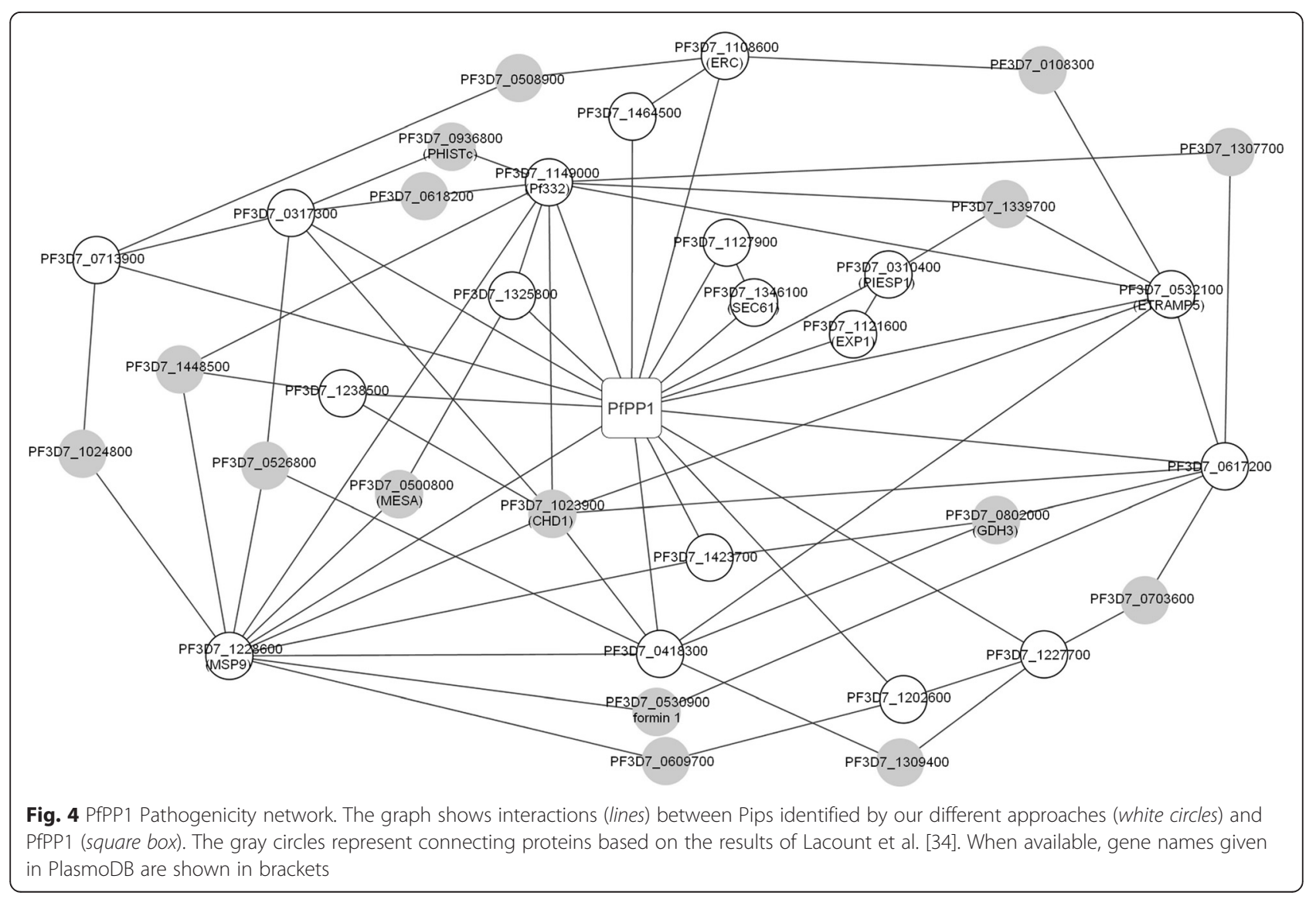


BSA-sepharose beads or PP1-beads overnight at $4{ }^{\circ} \mathrm{C}$. After 5 washings with $50 \mathrm{mM}$ Tris, $0.3 \mathrm{M} \mathrm{NaCl}$, proteins were eluted with $2 \times 0.5 \mathrm{ml}$ of $3 \mathrm{M} \mathrm{NaSCN}$. The proteins were then precipitated with acetone and separated on SDS-PAGE. No stained bands were observed for eluates of BSA-sepharose beads. Stained bands observed for eluates of PP1 column affinity were cut for MS/MS identification as previously described [37].

\section{Plasmid and yeast strain}

The cDNA library of Plasmodium falciparum, cloned in pGAD-HA vector, was purchased from Dualsystems Biotech. In this plasmid, the expressed parasite proteins are fused to the GAL4 activation domain. Yeast Y2HGold strain (Clontech) was transformed with the pGAD-cDNA library according to the method for highefficiency library scale transformation of Dualsystems Biotech, and allowed to form colonies on $150 \mathrm{~mm}$ plates with SD agar medium lacking leucine (SD/-Leu) at $30{ }^{\circ} \mathrm{C}$ (3-4 days). Y2HGold contains four integrated reporter genes (AUR1-C, HIS3, ADE2 and MEL1) under the control of three distinct GAL4 responsive promoters used to detect two-hybrid interaction and in order to reduce false positives. All clones were scraped, harvested with a freezing medium (YPDA medium with $25 \%$ glycerol) and stored in $1 \mathrm{ml}$ aliquots at $-80{ }^{\circ} \mathrm{C}$ for further experiments. This library-transformed yeast strain is referred below as the prey strain.

The cDNA encoding for $P$. falciparum protein phosphatase type-1 (PfPP1, PlasmoDB accession number: PF3D7_1414400) was cloned in the pGBKT7 vector (Clontech) to generate a PfPP1-pGBKT7 plasmid allowing the production of PfPP1 fused with the GAL4 DNA binding domain. Y187 yeast competent cells (Clontech) were then transformed with this construct according to the manual of Yeastmaker ${ }^{\text {Tax }}$ Yeast Transformation System 2 (Clontech). The expression of PfPP1 was checked by immunoblot using anti-GAL4BD antibody. This strain was used as a bait to screen protein interactions with the $P$. falciparum cDNA library by mating.

\section{Yeast two-hybrid assay}

All reagents and methods for yeast-two hybrid assays were from the Matchmaker ${ }^{\mathrm{m}}$ Gold Yeast Two-Hybrid System (Clontech).

One fresh and large colony of bait yeast strain (pGBKT7-PfPP1 in Y187) was inoculated into $50 \mathrm{ml}$ of $\mathrm{SD} /$-Trp/Kan (Kanamycin) liquid medium agitated at $250 \mathrm{rpm}, 30{ }^{\circ} \mathrm{C}$ until the OD600 reached 0.8 . The supernatant was discarded after centrifugation for $5 \mathrm{~min}$ at $1,000 \mathrm{~g}$. The pellet was suspended in $5 \mathrm{ml}$ of $\mathrm{SD} /$-Trp/Kan liquid medium ([cells] $>1 \times 10^{8} / \mathrm{ml}$ ). $1 \mathrm{ml}$ of library prey strain (after rechecking the titer) and $5 \mathrm{ml}$ of bait strain $\mathrm{Y} 187$ were combined with $45 \mathrm{ml}$ of
2xYPDA liquid medium and incubated for $20-24 \mathrm{~h}$ at $30{ }^{\circ} \mathrm{C}$ at $40 \mathrm{rpm}$. The culture was centrifuged for $10 \mathrm{~min}$ at $1,000 \mathrm{~g}$, then $50 \mathrm{ml}$ of $0.5 x Y P D A$ liquid medium (with $50 \mu \mathrm{g} / \mathrm{ml} \mathrm{Kan}$ ) was added to resuspend the pellet. After a centrifugation for $10 \mathrm{~min}$, cells were suspended in $10 \mathrm{ml}$ of $0.5 x Y P D A$ liquid medium (with $50 \mu \mathrm{g} / \mathrm{ml} \mathrm{Kan}$ ) and the total volume was measured. To calculate the number of screened clones and the mating efficiency, $100 \mu \mathrm{l}$ of the fusion culture (diluted by $10^{1}$ gradient) were plated on the selective medium $\mathrm{SD} /-\mathrm{Trp}$, $\mathrm{SD} /$-Leu, and SD/-Trp/-Leu (Double dropout medium, DDO) and incubated for $3-5$ days at $30{ }^{\circ} \mathrm{C}$. More than 1 million diploids were screened to maximize chances of detecting genuine interactions on Aureobasidin A (AbA) plates. The remaining fusion culture was spread onto selective medium SD/-Trp/-Leu/Kan supplemented with $125 \mathrm{ng} / \mathrm{ml}$ AbA (DDO/A), $200 \mu \mathrm{l}$ per $150 \mathrm{~mm}$ plates and incubated for $3-7$ days at $30{ }^{\circ} \mathrm{C}$. Colonies obtained were re-streaked onto higher stringency $\mathrm{SD} /$-Trp/-Leu/-His/AbA/Kan (TDO/A, Triple dropout supplemented with $\mathrm{AbA}$ ) and $\mathrm{SD} /$-Trp/-Leu/-His/-Ade/ $\mathrm{AbA} / \mathrm{Kan}$ (QDO/A, Quadruple dropout supplemented with AbA) agar plates. This screening was carried out five times independently.

\section{Identification of potential Pips}

The prey plasmids from positive yeast clones were isolated using the Plasmid DNA Purification kit (Macherey-Nagel). To facilitate yeast lysis, the equivalent of $100 \mu \mathrm{l}$ of glass beads (Sigma) was added in the resuspension buffer. To amplify the plasmid obtained, it was transformed to $E$. coli DH5 $\alpha$ cells (Life Technologies) followed by selection on LB/Ampicillin and LB/Kanamycin plates. Plasmids were isolated once again using the Plasmid DNA Purification kit and then to estimate the sizes of the specific inserts on positive prey plasmids, plasmids were digested using the Sfil restriction enzyme.

The positive prey plasmids were characterized by sequencing and BLAST searches to identify the corresponding P. falciparum genes in the PlasmoDB database (v24).

\section{In silico screening}

The consensus sequence used to identify potential interactors of PfPP1, was [KR][KR][ACHKMNQRSTV]V [CHKNQRST][FW]. It was based on the crystal of PP1 with a RRVSFA peptide [38] and on consensus sequences defined by different publications [12, 30, 31]. After identification of the putative partners, the positions -10 to +10 of $\mathrm{RVxF}$ motifs were aligned by BioEdit software (v7.2.5) to establish a new consensus sequence.

\section{Recombinant proteins expression and purification}

In order to verify the interaction between PfPP1 and its new interactors, His-tagged recombinant proteins were 
produced. Concerning Pips from $\mathrm{Y} 2 \mathrm{H}$ screening, the recombinant proteins correspond to the fragment identified during the screening (Additional file 6: Table S5). For Pips from in silico screening, the $\mathrm{A} / \mathrm{T}$ rich regions or acidic amino acids were eliminatory to avoid a lack of expression in E.coli. The different RVxF motifs were placed in the middle of recombinant proteins. The chosen coding regions for Pips were obtained by PCR with the primers mentioned in Additional file 10: Table S6 using the Advantage 2 Polymerase Mix (Clontech). The PCR conditions consisted of $10 \mathrm{~min}$ at $94{ }^{\circ} \mathrm{C}$ followed by 35 cycles at $94{ }^{\circ} \mathrm{C}(45 \mathrm{~s}), 56{ }^{\circ} \mathrm{C}$ or $58{ }^{\circ} \mathrm{C}$ (1 min) and $68{ }^{\circ} \mathrm{C}(1 \mathrm{~min} 30)$, finished by $7 \mathrm{~min}$ at $68^{\circ} \mathrm{C}$. To examine the role of RVxF binding motif, mutated constructs (KSVSF to KSASA for PF3D7_0919900, and the introduction of a stop in the second position of the KKVRF motif for PF3D7_0220000) were obtained by a PCR-based site-directed mutagenesis approach using the wild pQE30-PF3D7_0919900 and pETDuet-PF3D7_0220000 constructions as templates, the primers mentioned in Additional file 10: Table S6 and Isis DNA polymerase (MP Biomedicals). The mutations were checked by sequencing.

For the expression of Pips, the pETDuet-1 (Novagen) or pQE30 (Qiagen) expression system and the In-Fusion HD Cloning system (Clontech) were used according to the supplier's instructions. The plasmids and restriction sites are mentioned in Additional file 10: Table S6. The constructions obtained were checked by sequencing and transformed in One Shot ${ }^{\circ}$ BL21 Star ${ }^{\text {rem }}$ (DE3) Chemically Competent $E$. coli cells (Life Technologies) for expression.

The expression of His6-Pips was carried out in the presence of $0.5 \mathrm{mM}$ IPTG at $37{ }^{\circ} \mathrm{C}$ for $2 \mathrm{~h}$. Cells were harvested in sonication buffer $(20 \mathrm{mM}$ Tris, $500 \mathrm{mM}$ $\mathrm{NaCl}, 6 \mathrm{M}$ Guanidine, $20 \mathrm{mM}$ Imidazole and protease inhibitor cocktail (Roche), $\mathrm{pH}$ 7.5). Recombinant proteins were purified according to manufacturer's instructions by $\mathrm{Ni}^{2+}$-NTA agarose beads (Macherey Nagel). Washing steps were performed with a buffer containing $20 \mathrm{mM}$ Tris, $500 \mathrm{mM} \mathrm{NaCl}$ and $20 \mathrm{mM}$ imidazole, $\mathrm{pH}$ 7.5. Elution was done with a buffer containing $20 \mathrm{mM}$ Tris, $500 \mathrm{mM} \mathrm{NaCl}$ and $600 \mathrm{mM}$ imidazole, $\mathrm{pH}$ 7.5. The eluted proteins were dialyzed against $20 \mathrm{mM}$ Tris, $500 \mathrm{mM} \mathrm{NaCl}$, pH 7.5.

PfPP1 was produced as described above [16] with a dialysis buffer containing $20 \mathrm{mM}$ Tris, $500 \mathrm{mM} \mathrm{Nacl}$ and $1 \mathrm{mM} \mathrm{MnCl} 2$, $\mathrm{pH} 7.5$.

The produced proteins were quantified with the Pierce $^{\mathrm{Tm}}$ BCA Protein Assay Kit (Life Technologies) and checked by western blot. Soluble proteins were separated on a 4-20\% SDS-PAGE and subsequently blotted onto nitrocellulose. The blots were probed with antiHis antibody (1:2000 dilution) (Qiagen). As secondary antibody, a horseradish peroxidase-labeled anti-mouse
IgG (1:20000 dilution) was used, followed by chemiluminescence detection with SuperSignal ${ }^{\text {st }}$ West Dura Extended Duration Substrate (Life Technologies).

\section{Measurement of Pips binding}

Binding of Pips to PfPP1 was assessed by an ELISAbased assay as previously described [17]. The plates were coated with $25 \mathrm{pmol}$ of each Pips in PBS overnight at $4{ }^{\circ} \mathrm{C}$. In these experiments, recombinant PfI 2 and PfI3 $[16,17]$ and BSA were used as positive and negative controls respectively. The statistical significance was calculated with the Mann-Whitney $U$ test for nonparametric data and $p<0.05$ was considered significant.

\section{Bioinformatic analysis}

The different binding motifs were identified using the tool "Protein Motif Pattern" available on PlasmoDB website. For biological functions of Pips, only the putative or characterized functions were taken into account. The GO annotation of unknown proteins was not retained. For functional analysis, the different protein subnetworks were based on the results from LaCount [34] and our interactions with PfPP1. After manual correction, they were visualized on Cytoscape (v3.2.1). The Venn diagram was established from Venny [39].

\section{Availability of data and materials}

All genome and protein sequence files are available through PlasmoDB (http://plasmodb.org/plasmo/) and GenBank (http://www.ncbi.nlm.nih.gov/protein/) and the data are included in the manuscript and in Additional file 1: Table S1, Additional file 2: Table S2, Additional file 3: Table S3, Additional file 4: Table S4, Additional file 6: Table S5, Additional file 7: Figure S2, Additional file 8: Figure S3, and Additional file 9: Figure S4.

\section{Additional files}

Additional file 1: Table S1. Pips identified by affinity chromatography/ mass spectrometry. (XLSX $10 \mathrm{~kb}$ )

Additional file 2: Table S2. Common Pips between $P$. falciparum and other species. (XLSX 13 kb)

Additional file 3: Table S3. Pips identified by Yeast two-hybrid screening. (XLSX $24 \mathrm{~kb}$ )

Additional file 4: Table S4. Pips identified by genome in silico analysis. (XLSX 13 kb)

Additional file 5: Figure S1. Production of Pips in E. coli. Immunoblot assay of recombinant Pips. (PDF $143 \mathrm{~kb}$ )

Additional file 6: Table S5. Recombinant proteins produced. (XLSX $15 \mathrm{~kb}$ ) Additional file 7: Figure S2. Conservation of human and $\mathrm{Pf} H 2 \mathrm{~A}$ and H2B. Global alignments using BioEdit software. (DOCX 58 kb)

Additional file 8: Figure S3. Global alignment between in silico Pips. The different protein sequences flanking the RVXF motifs were aligned using BioEdit software. (DOCX $463 \mathrm{~kb}$ ) 
Additional file 9: Figure S4. PfPP1 interaction networks. Transcription/ DNA maintenance and Folding/Proteolysis subnetworks are shown. (PNG $141 \mathrm{~kb}$ )

Additional file 10: Table S6. List of primers for recombinant proteins expression. (DOCX $30 \mathrm{~kb}$ )

\section{Abbreviations}

AbA: Aureobasidin A; DDO: Double dropout medium; GAL4AD: GAL4 activation domain; HSP: Heat shock protein; 12: Inhibitor 2; 13: Inhibitor 3; Kan: Kanamycin; KO: Knock out; LRR1: Leucine Rich Repeat 1; Pf: Plasmodium falciparum; Pips: PP1 interacting proteins; PP1: Protein Phosphatase 1; TDO: Triple dropout medium; Y2H: Yeast two-hybrid.

\section{Competing interests}

There are no competing interests by any of the contributing authors.

\section{Authors' contributions}

JK designed the study. TH, CDW and AL, performed experiments. TH, CDW, $A L, C P$, and JK analyzed data. TH, CDW, CP and JK wrote the paper. All authors read, contributed feedback to, and approved the final manuscript.

\section{Acknowledgments}

We thank Hervé Drobeca for his technical assistance and Dr Raymond J Pierce for his critical reading of the manuscript. This work is supported by CNRS, Inserm, and Université Lille Nord de France.

\section{Received: 7 October 2015 Accepted: 7 March 2016}

\section{Published online: 17 March 2016}

\section{References}

1. Doerig C, Rayner JC, Scherf A, Tobin AB. Post-translational protein modifications in malaria parasites. Nat Rev Microbiol. 2015;13(3):160-72.

2. Guttery DS, Poulin B, Ramaprasad A, Wall RJ, Ferguson DJ, Brady D, Patzewitz EM, Whipple S, Straschil U, Wright MH, et al. Genome-wide functional analysis of Plasmodium protein phosphatases reveals key regulators of parasite development and differentiation. Cell Host Microbe. 2014;16(1):128-40.

3. Dobson S, May T, Berriman M, Del Vecchio C, Fairlamb AH, Chakrabarti D, Barik S. Characterization of protein Ser/Thr phosphatases of the malaria parasite, Plasmodium falciparum: inhibition of the parasitic calcineurin by cyclophilin-cyclosporin complex. Mol Biochem Parasitol. 1999;99(2):167-81.

4. Kumar R, Adams B, Oldenburg A, Musiyenko A, Barik S. Characterisation and expression of a PP1 serine/threonine protein phosphatase (PfPP1) from the malaria parasite. Plasmodium falciparum. 2002;1:5.

5. Mamoun CB, Sullivan Jr DJ, Banerjee R, Goldberg DE. Identification and characterization of an unusual double serine/threonine protein phosphatase $2 \mathrm{C}$ in the malaria parasite Plasmodium falciparum. J Biol Chem. 1998: 273(18):11241-7.

6. Bhattacharyya MK, Hong Z, Kongkasuriyachai D, Kumar N. Plasmodium falciparum protein phosphatase type 1 functionally complements a glc 7 mutant in Saccharomyces cerevisiae. Int J Parasitol. 2002;32(6):739-47.

7. Yokoyama D, Saito-Ito A, Asao N, Tanabe K, Yamamoto M, Matsumura T. Modulation of the growth of Plasmodium falciparum in vitro by protein serine/threonine phosphatase inhibitors. Biochem Biophys Res Commun. 1998;247(1):18-23.

8. Gallego M, Virshup DM. Protein serine/threonine phosphatases: life, death, and sleeping. Curr Opin Cell Biol. 2005;17(2):197-202.

9. Fardilha M, Esteves SL, Korrodi-Gregorio L, da Cruz e Silva OA, da Cruz e Silva FF. The physiological relevance of protein phosphatase 1 and its interacting proteins to health and disease. Curr Med Chem. 2010;17(33):3996-4017.

10. Bollen M, Peti W, Ragusa MJ, Beullens M. The extended PP1 toolkit: designed to create specificity. Trends Biochem Sci. 2010;35(8):450-8.

11. Huang HB, Horiuchi A, Watanabe T, Shih SR, Tsay HJ, Li HC, Greengard P, Nairn AC. Characterization of the inhibition of protein phosphatase-1 by DARPP-32 and inhibitor-2. J Biol Chem. 1999;274(12):7870-8.

12. Wakula P, Beullens M, Ceulemans H, Stalmans W, Bollen M. Degeneracy and function of the ubiquitous RVXF motif that mediates binding to protein phosphatase-1. J Biol Chem. 2003;278(21):18817-23.

13. Daher W, Browaeys E, Pierrot C, Jouin H, Dive D, Meurice E, Dissous C, Capron M, Tomavo S, Doerig C, et al. Regulation of protein phosphatase type 1 and cell cycle progression by PfLRR1, a novel leucine-rich repeat protein of the human malaria parasite Plasmodium falciparum. Mol Microbiol. 2006;60(3):578-90.

14. Daher W, Pierce R, Khalife J. Census, molecular characterization and developmental expression of Leucine-Rich-Repeat proteins in Plasmodium falciparum. Mol Biochem Parasitol. 2007;155(2):161-6.

15. Daher W, Oria G, Fauquenoy S, Cailliau K, Browaeys E, Tomavo S, Khalife J. A Toxoplasma gondii leucine-rich repeat protein binds phosphatase type 1 protein and negatively regulates its activity. Eukaryot Cell. 2007;6(9):1606-17.

16. Freville A, Landrieu I, Garcia-Gimeno MA, Vicogne J, Montbarbon M, Bertin B, Verger A, Kalamou H, Sanz P, Werkmeister E, et al. Plasmodium falciparum inhibitor-3 homolog increases protein phosphatase type 1 activity and is essential for parasitic survival. J Biol Chem. 2012;287(2):1306-21.

17. Freville A, Cailliau-Maggio K, Pierrot C, Tellier G, Kalamou H, Lafitte S, Martoriati A, Pierce RJ, Bodart JF, Khalife J. Plasmodium falciparum encodes a conserved active inhibitor-2 for Protein Phosphatase type 1: perspectives for novel anti-plasmodial therapy. BMC Biol. 2013;11:80.

18. Freville A, Tellier G, Vandomme A, Pierrot C, Vicogne J, Cantrelle FX, Martoriati A, Cailliau-Maggio K, Khalife J, Landrieu I. Identification of a Plasmodium falciparum inhibitor-2 motif involved in the binding and regulation activity of protein phosphatase type 1. FEBS J. 2014;281(19):4519-34.

19. Flores-Delgado G, Liu CW, Sposto R, Berndt N. A limited screen for protein interactions reveals new roles for protein phosphatase 1 in cell cycle control and apoptosis. J Proteome Res. 2007;6(3):1165-75.

20. Fardilha M, Esteves SL, Korrodi-Gregorio L, Vintem AP, Domingues SC, Rebelo S, Morrice N, Cohen PT, da Cruz e Silva QA, da Cruz e Silva EF, et al. Identification of the human testis protein phosphatase 1 interactome. Biochem Pharmacol. 2011;82(10):1403-15.

21. Fromont-Racine M, Rain JC, Legrain P. Toward a functional analysis of the yeast genome through exhaustive two-hybrid screens. Nat Genet. 1997; 16(3):277-82.

22. Chidley C, Haruki H, Pedersen MG, Muller E, Johnsson K. A yeast-based screen reveals that sulfasalazine inhibits tetrahydrobiopterin biosynthesis. Nat Chem Biol. 2011;7(6):375-83.

23. Logan MR, Nguyen T, Szapiel N, Knockleby J, Por H, Zadworny M, Neszt M, Harrison $\mathrm{P}$, Bussey $\mathrm{H}$, Mandato $\mathrm{CA}$, et al. Genetic interaction network of the Saccharomyces cerevisiae type 1 phosphatase Glc7. BMC Genomics. 2008;9:336.

24. Costanzo M, Baryshnikova A, Bellay J, Kim Y, Spear ED, Sevier CS, Ding H, Koh JL, Toufighi K, Mostafavi S et al. The genetic landscape of a cell. Science. 2010;327(5964):425-31.

25. Walsh EP, Lamont DJ, Beattie KA, Stark MJ. Novel interactions of Saccharomyces cerevisiae type 1 protein phosphatase identified by single-step affinity purification and mass spectrometry. Biochemistry. 2002;41(7):2409-20.

26. Peti W, Page R. Strategies to make protein serine/threonine (PP1, calcineurin) and tyrosine phosphatases (PTP1B) druggable: achieving specificity by targeting substrate and regulatory protein interaction sites. Bioorg Med Chem. 2015;23(12):2781-5.

27. Plasmodium Genomics Resource. http://plasmodb.org/plasmo/. Accessed 28 Sep 2015

28. Dastidar EG, Dzeyk K, Krijgsveld J, Malmquist NA, Doerig C, Scherf A, Lopez-Rubio JJ. Comprehensive histone phosphorylation analysis and identification of Pf14-3-3 protein as a histone $\mathrm{H} 3$ phosphorylation reader in malaria parasites. PLoS One. 2013;8(1):e53179.

29. Bazzi M, Mantiero D, Trovesi C, Lucchini G, Longhese MP. Dephosphorylation of gamma $\mathrm{H} 2 \mathrm{~A}$ by Glc7/protein phosphatase 1 promotes recovery from inhibition of DNA replication. Mol Cell Biol. 2010;30(1):131-45.

30. Hendrickx A, Beullens M, Ceulemans H, Den Abt T, Van Eynde A, Nicolaescu E, Lesage $B$, Bollen M. Docking motif-guided mapping of the interactome of protein phosphatase-1. Chem Biol. 2009;16(4):365-71.

31. Meiselbach H, Sticht H, Enz R. Structural analysis of the protein phosphatase 1 docking motif: molecular description of binding specificities identifies interacting proteins. Chem Biol. 2006;13(1):49-59.

32. Breitkreutz A, Choi H, Sharom JR, Boucher L, Neduva V, Larsen B, Lin ZY, Breitkreutz BJ, Stark C, Liu G, et al. A global protein kinase and phosphatase interaction network in yeast. Science. 2010;328(5981):1043-6.

33. Ho Y, Gruhler A, Heilbut A, Bader GD, Moore L, Adams SL, Millar A, Taylor P, Bennett K, Boutilier K et al. Systematic identification of protein complexes in Saccharomyces cerevisiae by mass spectrometry. Nature. 2002;415(6868):180-3.

34. LaCount DJ, Vignali M, Chettier R, Phansalkar A, Bell R, Hesselberth JR, Schoenfeld LW, Ota I, Sahasrabudhe S, Kurschner C, et al. A protein 
interaction network of the malaria parasite Plasmodium falciparum. Nature. 2005;438(7064):103-7.

35. Rodent Malaria genetically modified Parasites. http://www.pberghei.eu/. Accessed 28 Sep 2015.

36. van Ooij C, Tamez P, Bhattacharjee S, Hiller NL, Harrison T, Liolios K, Kooij T, Ramesar J, Balu B, Adams J, et al. The malaria secretome: from algorithms to essential function in blood stage infection. PLoS Pathog. 2008;4(6):e1000084.

37. Sergeant N, Bombois S, Ghestem A, Drobecq H, Kostanjevecki V, Missiaen C, Wattez A, David JP, Vanmechelen E, Sergheraert C, et al. Truncated betaamyloid peptide species in pre-clinical Alzheimer's disease as new targets for the vaccination approach. J Neurochem. 2003;85(6):1581-91.

38. Egloff MP, Johnson DF, Moorhead G, Cohen PT, Cohen P, Barford D. Structural basis for the recognition of regulatory subunits by the catalytic subunit of protein phosphatase 1. EMBO J. 1997;16(8):1876-87.

39. Oliveros JC. Venny. An interactive tool for comparing lists with Venn's diagrams. http://bioinfogp.cnb.csic.es/tools/venny/index.html (2007-2015). Accessed 28 Sep 2015

Submit your next manuscript to BioMed Central and we will help you at every step:

- We accept pre-submission inquiries

- Our selector tool helps you to find the most relevant journal

- We provide round the clock customer support

- Convenient online submission

- Thorough peer review

- Inclusion in PubMed and all major indexing services

- Maximum visibility for your research

Submit your manuscript at www.biomedcentral.com/submit
) Biomed Central 